UDC: 821.134.3.09 Redol A.

DOI: https://doi.org/10.18485/beoiber.2018.2.1.9

\author{
André Carneiro Ramos ${ }^{1}$ \\ Universidade do Estado do Rio de Janeiro \\ Brasil
}

\title{
UM MODO DE SOBREVIVER AO VAZIO: O NEORREALISMO PORTUGUÊS EM ALVES REDOL E VERGÍLIO FERREIRA
}

\begin{abstract}
Resumo
Perante os riscos de se abordar um assunto tão relevante para a literatura portuguesa, que alicerçou ainda mais as bases de sua modernidade no romance, aqui se desenvolverá uma breve reflexão sobre o Neorrealismo em Portugal e seu caráter de militância, denúncia e reflexão, com escritores da importância de Alves Redol e Vergílio Ferreira, cada um à sua maneira, representando a impossibilidade de o homem se desligar de sua dimensão social. Mais especificamente, tal proposição me leva a pensar na fase existencialista do autor de Estrela polar (1962), indagando sobre até que ponto ele teria se afastado mesmo das realidades sociais propagadas pelo movimento. Para esse percurso, exponho duas das perguntas que mais me interessam: a) o personagem Alberto, do romance Aparição, enquanto um "ser-aî" heideggeriano, poderia fazer a diferença para si mesmo num primeiro momento, objetivando, tempos depois, sentir-se apto para abraçar a coletividade? b) Isso poderia fazer parte de uma espécie de projeto de Vergílio Ferreira, que assim qualificaria sua obra como um todo intercambiante? Assim sendo, sintonizados pela premissa principal, críticos como João Laranjeira Henriques, José Carlos Barcellos, José Rodrigues Paiva, Isabel Margato e Carlos Reis me levam a crer que a aproximação entre os escritores elencados representa muito bem o delineamento de fecundas possibilidades de compreensão/releitura das obras literárias envolvidas, ressaltando-lhes a atualidade.
\end{abstract}

Palavras-chave: Neorrealismo Português, Existencialismo, Alves Redol, Vergílio Ferreira.

\section{A WAY TO SURVIVE EMPTINESS: \\ PORTUGUESE NEOREALISM IN ALVES REDOL AND VERGÍLIO FERREIRA}

\begin{abstract}
Faced with the risks of approaching a subject so relevant to Portuguese literature, which further grounded its modernity in the novel, here a brief reflection on Neorealism in Portugal will be developed, including its character of militancy, denunciation and reflection, with writers of the stature of Alves Redol and Vergilio Ferreira, each in his own way, representing the impossibility of man detaching himself from his

1 andremacartney@hotmail.com
\end{abstract}


social dimension. More specifically, this proposition leads me to think about the existentialist phase of the author of Estrela Polar (1962), asking how far he would have departed even from the social realities propagated by the movement. For this course, I present two of the questions that interest me most: a) could the character Alberto, from the novel Aparição, as a Heideggerian "there-being", make a difference for himself at first, aiming, after a while, to feel fit to embrace the collective? b) Could this be part of a kind of project by Vergílio Ferreira, who would thus qualify his work as an interchangeable whole? Thus, attuned to the main premise, critics such as João Laranjeira Henriques, José Carlos Barcellos, José Rodrigues Paiva, Isabel Margato and Carlos Reis lead me to believe that the rapprochement between the writers listed very well represents the design of prolific possibilities of comprehension/rereading of the literary works involved, highlighting the current events.

Key words: Portuguese Neorealism, Existentialism, Alves Redol, Vergílio Ferreira.

Quando se pensa em Neorrealismo, muitas vertentes se apresentam à memória, e uma das mais relevantes sem dúvida é a do cinema italiano, que soube muito bem explorar as vicissitudes do homem em meio aos desvarios sociais de um mundo regido pelo Capitalismo. Um filme que se tornou quase que sinônimo dessa vanguarda é Ladrôes de bicicleta (1948), cuja história é atualíssima: um pai de família, desempregado na Roma do pós-Segunda Guerra, recebe uma oferta de emprego como afixador de cartazes pelas ruas da cidade, sendo que a única condição para a vaga era que tivesse uma bicicleta. Com muito custo, consegue adquirir uma; entretanto, depois de vê-la roubada, suas esperanças e vida desmoronam.

E para além das telas de cinema, aquilo que o Neorrealismo mais potencializou em sua vida útil foi uma espécie de tomada de posição ideológica por parte dos intelectuais, levando-se em conta uma estreita vinculação entre solidariedade e atitude, isso perante as mazelas e sofrimento da "plebe". Visto de um ângulo europeu, enquanto os países destroçados pela guerra se reconstruíam, os discursos da Resistência - que dentre outras coisas execravam a horrível possibilidade dos campos de concentração nazistas - teriam sido a gênese do movimento, encabeçado por escritores e artistas surgidos nos anos 30, e que posteriormente insistiram com relevantes dinâmicas antifascistas.

O curioso é que, no caso de Portugal, algumas “categorias especiais" acabariam por evidenciar pequenas disjunções na caracterização de seu Neorrealismo, como por exemplo, ao levarem para o campo da discussão/criação literária orientações um pouco menos empenhadas na intervenção social, algo que praticamente representava a estética do movimento. Pois para os portugueses, o momento era também de se tentar romper com certos estigmas estabelecidos nos Oitocentos, como por exemplo, a manutenção de um estado provincial enraizado nas tradições, com sua herança cosmopolita sendo veementemente aceita sob muitos aspectos pelo regime salazarista.

O quadro dá o que pensar. E o Neorrealismo se iniciou mesmo por lá no início dos 40, acontecendo em paralelo com o Estado Novo, ou melhor, na contramão de seu totalitarismo, oferecendo a reflexão de uma perspectiva de mundo mais equânime. Nas letras lusitanas, segundo o pesquisador João Laranjeira Henriques (2010), para que isso se 
demonstrasse, o escritor deveria se desvencilhar dos arquétipos românticos (cito aqui igualmente os da linhagem estético-presencista) intersubjetivos, de certo modo paralisantes, para logo em seguida explorar uma ação intelectual que atuasse didaticamente transformando a realidade do entorno (pelo menos arriscando isso fazer), como num grande engajamento.

Curiosamente, a contenda "puristas" versus "socialistas" (na falta de palavra melhor) acabaria ganhando as páginas de alguns periódicos portugueses da época, que funcionavam como campo de batalha argumentativa entre as referidas partes, com os "neorrealistas" confrontando as posturas da geração anterior. Num dos números do semanário $O$ Diabo, por exemplo - que em seus poucos anos de circulação se firmou como órgão de debate e teorização do Neorrealismo português - evidenciou-se a seguinte indagação a partir do artigo "A crítica impossível”, de João Pedro de Andrade: "(...) deve a arte ter como diretriz um ideal filosófico, social, religioso, ou, ao contrário, confinar-se numa esfera própria e isolada, sem que a interessem, a não ser por incidente, as mil misérias e lutas de que a vida é feita?" (Henriques 2010: 35-36).

Seja como for, a crítica literária separa em dois momentos o início do Neorrealismo português. Num primeiro impulso, evidencia-se o polemismo (numa reação ao já citado esteticismo exercido pelo grupo da revista Presença); mas também oferece uma reflexão de índole doutrinal marcada pelo marxismo/leninismo. $O$ fato é que essa base ideológica se distancia substancialmente das preocupações sociais do RealismoNaturalismo do século XIX. Basta pensarmos no aspecto sociológico tratado por Eça de Queirós, com sua aristocracia decadente, e o protagonismo que tematiza o romance neorrealista da primeira fase (a saber, as classes trabalhadoras). Num segundo momento, que se firmará a partir da década de 50, nota-se uma maior atenção às questões de caráter estético.

Dito isso, faz-se notória a predileção dos neorrealistas pela narrativa. Ao mesmo tempo em que valorizam a objetividade (acentuando o caráter ilustrativo e documental dos relatos), possíveis elementos fantásticos são totalmente colocados de lado, pois a ficção, nessa perspectiva, deve ser o espelho da realidade. Ao mesmo tempo, contrastando com a geração oitocentista, estão suspensos os psicologismos. Por exemplo, os personagens se coletivizam (destacam-se tipos que encarnam os valores, aspirações e frustrações do grupo, muitos deles como vítimas de exploração social); nessa monta, muito provável que o subjetivismo de um Mário de Sá-Carneiro, um Almada Negreiros, ou um Branquinho da Fonseca, cedesse lugar ao registro testemunhal. E como tudo que é interessante, vejam essa oportuna colocação do saudoso professor José Carlos Barcellos (2004):

Por outras palavras, a estética literária neo-realista se define em termos semânticos e pragmáticos, mas não em termos sintáticos. Ou seja, não há um estilo neorealista propriamente dito: cada autor pôde efetivamente experimentar diferentes 
técnicas narrativas, registros lingüísticos e recursos literários em função da consecução dos objetivos semânticos e pragmáticos do Neo-Realismo comuns a todos eles. É o que se observa de forma inequívoca quando se comparam obras como Gaibéus (1940), de Alves Redol, Cerromaior (1943), de Manuel da Fonseca, Vagão J(1946), de Vergílio Ferreira, ou Jogos de azar (1946), de Cardoso Pires, por exemplo.

Muito apropriada, portanto, essa menção a Gaibéus e a Alves Redol (1911-1969), cujo universo narrativo se centraliza nos ceifadores de arroz assalariados do Tejo. Tratase, esclareço, do romance pioneiro do Neorrealismo português em sua primeira fase. $\mathrm{E}$ talvez também o caso mais notável de influência de uma epígrafe em toda uma geração literária. Nela se pode ler, sob a forma de microestrutura, o programa do movimento: "Este romance não pretende ficar na literatura como obra de arte. Quer ser, antes de tudo, um documentário humano fixado no Ribatejo. Depois disso, será o que os outros entenderem" (1983: 9).

Não obstante, curioso é o fato de que tal citação também não deixe de exibir uma aporia: na condição substancial de texto, trata-se de um documento de denúncia e expressão de aspirações/emancipação social; mas também é, sem sombra de dúvida, um objeto estético, apesar de na primeira fase do Neorrealismo os imperativos ideológicos suplantarem em polemizações o trabalho literário.

Nesse ínterim, a certa altura no referido romance imperativos de natureza marxista podem ser facilmente verificados, sem contar a costumeira denúncia da exploração do homem pelo próprio homem; na superação desse abuso, lê-se, claro, a concomitante expressão de um desejo emancipatório de mudança.

Como exemplo, destaco o pungente fragmento retirado do capítulo "Porto de todo o mundo", em que dois sofridos trabalhadores se reconhecem nessa subalterna e explorada condição e, esperançosos, sonham com uma vida melhor:

Os dois gaibéus queriam agora partir, agora mesmo, se fosse possível. Aquele companheiro era louco, não dizia coisa com coisa. Dali não se podia ir por aquele rio para toda a parte do mundo, nem as Áfricas e o Brasil estavam dentro dos homens. (...) Um ano mais e a vida começaria então. Aquilo assim não era viver. Vida nova em terras novas. E ergueram-se. O outro ceifeiro continuava estendido na areia, de olhos cerrados, e não os sentiu partir. Não respondeu, pelo menos, à saudação que lhe dirigiram. Caminhavam lado a lado, silenciosos, pensando no seu sonho - o sonho pertencia-lhes (1983: 182).

Para não fugir à regra, observa-se ainda em Gaibéus a incondicional despersonalização de seus elementos individuais. Reitera-se no livro um protagonismo definido nos termos de um conglomerado de personagens, com essa coletivização ("anonimato" ou "apagamento do indivíduo", caso prefiram) assumindo uma significação especial: o personagem central é uma classe, os coletores de arroz. 
Nesse sentido, o espaço assumiria uma total relevância, sobretudo porque as condições meteorológicas adversas - calor, frio, chuva - contribui até mesmo para um tom irônico do romance, evidentemente que num viés crítico associado às condições subumanas dos trabalhadores. Percebe-se também na diegese uma particular organização do tempo narrativo (algo modelar dentro da narratologia neorrealista), tendo sempre como pano de fundo um obsessivo presente - plasmado em ação repetitiva, tal qual Sísifo - conotando a alienação em que os trabalhadores se encontram afundados.

Mas se o Presencismo ${ }^{2}$ e o Neorrealismo haviam se posicionado ao mesmo tempo no entorno do psicológico e do social, a dimensão humana do universo ficcional de Vergílio Ferreira (1916-1996) incluiria a ambos. Considerada em seu conjunto, sua obra evoca não somente os problemas sociológicos, mas também a intersubjetividade. Nesse sentido, o autor impregna seus escritos (iniciando o processo em 1949, a partir do livro Mudança) de uma proposta filosófico-existencial traduzida na emergência de temas como solidão, morte, o trajeto do sujeito ao nada, ou melhor, à vida entendida como absurdo ${ }^{3}$, em que lhe são potencializadoras, evidentemente, as lições de Sartre e Camus.

Em linhas gerais, associa-se Vergílio Ferreira a uma vertente que aproxima mesmo o romance português novecentista de um viés mais filosófico, isso na construção de personagens que se voltam para si estando imersos em atribulações que lhes amoldam as respectivas naturezas. Inscreve-se, portanto, o problema cabal discutido em um de seus mais celebrados livros, Aparição (1959), inclusive lançado num momento em que o Existencialismo se delineava com potência maior na obra vergiliana.

Ao longo desse romance, nota-se o esforço do autor em descobrir no que significava e resultava o emaranhado de elucubrações que o personagem principal, Alberto Soares, se predispunha a viver entre passado, presente e futuro nos espaços de Évora, bem como no invólucro em que se transformava sua importante "casa do Alto". A inquietação que pude sentir como leitor (faço questão de mencionar) correlacionou-se aos sons/pensamentos/visões que o protagonista, sempre sob um viés ontológico, demonstra ao longo de suas reflexões/descrições; e sob uma ótica existencial, os acontecimentos narrados, bem como as ações dos personagens e a psicologia destes, seguem compondo um cenário que, a princípio, desperta angústia e medo; numa de suas várias frases impactantes o autor referencia: "Nesta casa enorme e deserta, nesta noite ofegante, neste silêncio de estalactites, a lua sabe a minha voz primordial» (Ferreira 1971: 9).

Medo do ser e do não-ser? É nessa direção que se estabelece o percurso dessa obra. O protagonista se vê preso/liberto a um temor sem explicação frente ao

2 Movimento artístico-literário que marcou a segunda fase do Modernismo português.

3 A temática do absurdo no Existencialismo diz respeito à noção de que não há um significado maior a ser encontrado no mundo além do básico sentido que lhe atribuímos; a literatura de Jean-Paul Sartre e Albert Camus retrata em muitos momentos personagens que vivenciam "na pele" tal situação (no caso dos referidos autores, associada sobremaneira a um viés político, evidentemente). 
imponderável, na tentativa de se descobrir, revelando-se numa "aparição fantástica das coisas". Esse esforço em se descortinar lhe permite ir ao encontro de uma assustadora e inevitável constatação, fato central em sua (nossa) existência: o homem é um ser caminhante para a morte.

Como se verifica, trata-se de uma prerrogativa que pode vir a despertar uma espécie de insurreição do personagem, alicerçada a um temor sem explicação. De qualquer modo, torna-se clara a certeza de que essa dúvida passaria a norteá-lo em seus momentos decisivos de epifania (ou "clarividência", como preferirem); Alberto Soares, pelo EU que o habita ${ }^{4}$, passará a seguir um necessário caminho de relativização das muitas "verdades absolutas" 5 que, na vida, insistem em nos interpelar/azucrinar:

$\mathrm{E}$, todavia, pesa-me como uma pata de violência a realidade da pessoa que somos. Há muita coisa a arrumar, a harmonizar, muita coisa a morrer. Mas por enquanto está viva. Por enquanto sinto a evidência de que sou eu que me habito, de que vivo, de que sou uma entidade, uma presença total, uma necessidade do que existe, porque só há eu a existir, porque eu estou aqui, arre!, estou aqui, EU, este vulcão sem começo nem fim, só actividade, só estar sendo, EU, esta obscura e incandescente e fascinante e terrível presença que está atrás de tudo o que digo e faço e vejo - e onde se perde e esquece. EU! Ora este "eu" é para morrer. (1971: 34).

Em meio a tudo isso, ao que se percebe é certo que Aparição pretende investigar as sombras do "ser-aî"6, aquele que Heidegger denominou como Dasein. Nessa evidência, num buscar do passado "à luz da lua e da razão", seria por demais poder recriá-lo sensivelmente com o auxilio da literatura, clareando/rasurando as "perfeições" que a nós são impostas cotidianamente; portanto, numa espécie de epopéia de si mesmo, esse EUpensante chamado Alberto (aberto), e que bem representa os homens-eleitos, se revela pelas mãos de Vergílio Ferreira como um inquiridor de realidades ocultas, por vezes sua (do escritor? do personagem?), por vezes do mundo, divulgada nos instantes de um encontro dele(s) consigo mesmo.

Se, portanto, cada época tem a sua verdade (palavras do autor), um matiz existencialista se definiria mais denso aqui, num viés atual pelos ajustamentos do Ser, e isso no universo em que the foi dado viver, conviver e sobreviver. Ora bem, o protagonista passa, então, a buscar-se no devir e na transcendência por meio de

${ }^{4}$ Para Heidegger, dizer "eu" se refere ao ente que sou enquanto sou-no-mundo.

${ }^{5}$ A filosofia, de um modo geral, defende que a existência de uma pluralidade de paradigmas conceituais enfraquece a idéia de que há mesmo uma "verdade absoluta". Para Descartes, por exemplo, não existe "verdade", mas várias verdades, isso de acordo com quantas abordagens científicas sejam possíveis de se comprovar; assim, os cientistas estarão sempre na convergência para uma compreensão mais ampla do que é o mundo, mas isso não quer dizer que seja possível apregoar uma "verdade última" sobre ele.

$6 \mathrm{Na}$ contemporaneidade, tal conceito trata das modalidades do "ser-em" da existência, evidenciando comportamentos caracterizadores da essência humana; ou seja: filosoficamente, tal "presença" hoje corrobora com o fato de o homem meramente existir, em sentido próprio. 
revelações desse porte, tornando-se acentuado em Aparição uma espécie de separação temporal. $O$ presente se fratura em passado e futuro, proporcionando a introspecção que o personagem anseia sentir por si só e que seria a responsável pela recriação de um reles momento, nos instante-chaves que formam a existência. Essa fração se configura na exegese vergiliana como uma espécie de genitora da eternidade, favorecendo-lhe num reencontro com as origens. Mas como?

Em uma sala vazia, banhada pelo luar do existir, Alberto passa a se considerar em si próprio, encontrando-se consciente por aquilo que descobre, ou melhor, relembra:

Sento-me aqui nesta sala vazia e relembro. Uma lua quente de verão entra pela varanda, ilumina uma jarra de flores sobre a mesa. Olho essa jarra, essas flores, e escuto o indício de um rumor de vida, o sinal obscuro de uma memória de origens. No chão da velha casa a água da lua fascina-me. (...) a lua sabe a minha voz primordial (...). (1971: 9).

A cada passagem onde a escrita se firma como um ato de devastação, nota-se que Alberto Soares, no questionamento de suas "verdades absolutas", tenta compreender o cerne de cada um (na iminência de uma coletividade?), por vezes na divisa entre pensamento e palavra (nota-se isso na escrita vergiliana); algo misterioso e obrigado a coexistir com um efeito desagregador. Mais uma vez, digna de nota é a ressonância metafísica que Aparição promove.

Como exemplo disso, em outra passagem, frente ao cadáver paterno, já não mais encontra a realidade do que ele (seu pai) foi, mas apenas um corpo inerte, destituído das características que o tornavam único perante o mundo. Diante de si mesmo, feito um espelhamento do pai, é-lhe conferida a certeza de que tal mistério, o tudo que lhe é determinado, transcende a consciência que o faz ter consciência; tendo a percepção ou não do que é a morte, descobre que sua idéia, sua abstração, não reside nas conceituações do EU, aquelas que usualmente pensava conhecer. $\mathrm{E}$ reflete que, consigo mesmo (conosco), tal processo igualmente se repetirá:

Como tu, meu velho. Aí estás à beira da cova, na urna aberta, para te reconhecermos pela última vez. Onde a tua pessoa, onde o que eras tu? Passam pela estrada os carros chiando. Vêm das vinhas, das vindimas, trazem o aroma da terra e da vida. Mas tu agora és apenas a tua imagem. Que é de ti? Ouço para lá dos teus lábios cerrados a tua palavra grave, vejo as tuas mãos erguerem-se, povoadas de um gesto que eras tu. Não! Quem te habitava não é. Viverás ainda na memória dos que te conheceram. Depois esses hão de morrer. Depois serás exactamente um nada, como se não tivesses nascido. Quantos crimes, vexames, remorsos, alegrias e projectos e traições e castigos e prêmios e tudo e tudo nos milhões de homens que passaram noutros séculos por esta pequena aldeia e souberam os seus sítios e a montanha e ribeira (...), e são hoje o nada integral, absoluto, pura ausência, nada-nada? Eis que começa a tua longa viagem para a 
vertigem das eras, para a desaparição do silêncio dos milênios. Sim, agora ainda vives para mim porque te sei. (1971: 36).

Portanto, há por aqui um esforço mesmo "existencialista" de entendimento/ questionamento da morte. Num mergulho vertical, ao vasculhar a condição humana "perdida" do pai, Alberto se abre para a finitude do ser; a dúvida do personagem sobre a elevação da essência do homem ao infinito, aquela em que muitos religiosamente acreditam, adquire já no início de Aparição uma fluidez dialógica, reflexiva. Como consolo, verifica-se que uma força peculiar de "presença" de quem vai embora é ainda mantida a nós por um tempo relativo, sobrevivendo através das lembranças que deixar, na medida em que mais verdadeiramente for sentida, compartilhada, vivida.

Mas voltemos às "categorias especiais" do neorrealismo português. Alguns rasgos narratológicos em Aparição me fizeram disso lembrar, ao passo que remeteram a um paulatino afastamento do rígido imperativo documentarista apregoado pelo movimento (sinalizadores de uma narratologia determinada por fins ideológicos). Seguem alguns exemplos.

Num primeiro rasgo: a construção do espaço se reduz quando comparado ao cânone dos romances neorrealistas. Se por exemplo em Gaibéus temos a descrição constante da paisagem aberta e natural onde se movem os trabalhadores, em Aparição predominam lugares que se interrelacionam à interioridade $e$ isolamento dos personagens.

Num segundo rasgo: o tempo cronológico deste último corresponde a algo mesmo distinto, pois os intervalos evocados pelo personagem Alberto Soares se relacionam a um passado recente. Tal narrador, na verdade, é "prisioneiro do presente da narração", e o curioso é que, ainda assim, pelo recurso da retrospectiva, é que somos apresentados à intriga da história. Logo, memória e relato nele se confundem de modo magistral.

E num terceiro rasgo: coadunado ao que agora foi dito, sua narração em primeira pessoa (em muitos momentos, num regime de "monólogo interior") se distancia também da comumente empregada nos romances neorrealistas, em oposição ao descritivismo das cenas e narrações em terceira pessoa. A onisciência do narrador de Alves Redol, por exemplo, contrasta diretamente com a autodiegese do narrador vergiliano.

Essas percepções de espaço, tempo e narração desfazem o pensamento daqueles que consideram a feitura de um romance dessa categoria como algo possivelmente fácil, no sentido de que um autor qualquer teria preferido prestar obediência às convenções romanescas. No caso de Aparição, constata-se que ele é: "(...) o "mais clássico" dos romances de Vergílio Ferreira, [e] é também, paradoxalmente, ou não, o seu romance "mais revolucionário"” (Paiva 2007: 114). E tudo isso me faz ajuizar o seguinte: olhar para - Neorrealismo Português apenas como um "movimento" literário de denúncia social é limitá-lo. Sobre o assunto afirma Isabel Margato: 
A conseqüência imediata da adoção desse pressuposto traduz-se na identificação dos textos neo-realistas como produções de um realismo inferior, que devem ser lidos, prioritariamente, como documentos de época. Acrescentando mais um dado, poderíamos dizer que grande parte da demarcação a que a produção neorealista ficou sujeita deve-se, principalmente, a um posicionamento crítico redutor que considera essas obras apenas como documentos políticos decalcados da e pela ideologia marxista (2008: 3).

Na realidade, um estudo atento das produções desse período é capaz de mostrar que o Neorrealismo em terras lusas não visava apenas a “ação”, visto que a preocupação com questões artísticas e/ou filosóficas também se destaca nos textos. Vergílio Ferreira é um autor que ilustra e "esgarça" tais "demarcações". O curioso é que, numa boa observação, Carlos Reis (1983) sinaliza que Gaibéus extravasaria qualidades estéticas que desmentiriam a sua utilização como um testemunho documental apenas. Haveria aqui, portanto, mais um ponto inusitado de convergência entre ambos os escritores?

Não disponho de tempo para refletir acerca dessa e de outras indagações. Muitas, por sinal. Mas o que me retorna agora são as perguntas que fiz lá no início. Respostas possíveis: a) sim, creio que Alberto, enquanto "ser-aî", construiu todo um arcabouço que não o deixou estagnar-se, sendo que por mais introspecto que ele pudesse agir, a sensação que temos é a de que o seu senso de moral o levaria, em situações cabíveis, rumo aos mais louváveis ideais coletivos; e b) penso ser bem plausível a ideia de a obra vergiliana corresponder a um projeto em sua totalidade, com os possíveis "intercâmbios" entre os livros representarem o seu intento maior, a relativização de paradigmas.

A partir dessas considerações, reflito que a passagem do referido autor, do Neorrealismo para o viés sartreano, tenha se firmado pelo que havia de continuidade entre as duas correntes: para ele, uma maneira "rasurante" de se encarar o hegelianismo (com sua tese-antítese-síntese), que como sabemos fundamentou a filosofia de Karl Marx e abriu caminhos para o Existencialismo.

Para terminar: sobre Alves Redol e Vergílio Ferreira, que a meu ver em muito potencializaram as vertentes do romance não só neorrealista e/ou existencialista, mas contemporâneo em Portugal (e fora dele), atuando como metonímia de interessantes transgressões geradoras de frutos, podemos agora unir a ponta deste final a um trecho de um poema de Manuel de Freitas (2010: 7), que bem representa essa condição ao mesmo tempo abissal e quotidiana, coletiva e individual, melancólica e, por isso mesmo, fundamental da prosa lusitana, portadora de elementos-chave a partir dos quais a literatura e o gênero romance, a nível mundial, invariavelmente se renovam, inclusive tendo nas experiências narradas pelos portugueses uma irretocável contribuição:

(...)

sinto-me estranho como em qualquer lugar, espião não da casa do amor mas na da 
morte quotidianamente vivida.

A melancolia pode às vezes ser isto,

um modo de sobreviver ao vazio, o comovido

jeito de pôr a mão sobre o mármore da mesa

e pedir outro Martíni, fresco

se faz favor.

\section{BIBLIOGRAFIA}

Barcellos, José Carlos. "Cerromaior e o neo-realismo português." Cuadernos da ABF 4.1 (2004): s. p. CiFEFiL. Web. 27 Out. 2016.

Ferreira, Vergílio. Aparição. Biblioteca Básico Verbo. Lisboa: Editorial Verbo, 1971. Impresso.

-. Um escritor apresenta-se. Introdução, prefácio e notas de Maria da Glória Padrão. Biblioteca de Autores Portugueses. Lisboa: Casa da Moeda, 1981. Impresso.

Freitas, Manuel de. A última porta. Lisboa: Assírio \& Alvim, 2010. Impresso.

Godinho, Helder. O universo imaginário de Vergílio Ferreira. Lisboa: Instituto Nacional de Investigação Científica, 1985. Impresso.

Henriques, João Laranjeira. "A Poesia no Neo-Realismo Português: Primeiras Manifestações e "Novo Cancioneiro"." Tese de doutoramento. Faculdade de Letras da Universidade de Lisboa, 2010. Não publicado.

Lopes, Óscar. Gaibéus: uma leitura cinqüentenária. Lisboa: Editorial Caminho, 1990. Impresso.

Margato, Isabel. "Notas sobre o Neo-Realismo português: um desejo de transformação." Via Atlântica 13 (2008): 43-56. Web. 27 Out. 2016.

Paiva, José Rodrigues de. Vergílio Ferreira: para sempre, romance-síntese e última fronteira de um território ficcional. Recife: Editora Universitária da UFPE, 2007. Impresso.

Redol, Alves. Gaibéus. Lisboa: Publicações Europa-América, 1983. Impresso.

Reis, Carlos. O discurso ideológico do Neo-Realismo português. Coimbra: Almedina, 1983. Impresso.

Torres, Alexandre Pinheiro. O Movimento Neo-Realista em Portugal na sua Primeira Fase. Lisboa: Instituto de Cultura e Língua Portuguesa, 1983. Impresso.

-. Os romances de Alves Redol. Lisboa: Morais Editora, s. d. Impresso.

Fecha de recepción: 28 de octubre de 2017. Fecha de aceptación: 28 de noviembre de 2017. 